\title{
Undergraduate College Faculty Workshops in OCEANOGRAPHY, 1987-1992
}

By John W. Farrington and A.L. Peirson, III

\section{$\mathrm{T}$} HE RECENT Ocean Sciences Meeting in San Diego, California. February 12-16, 1996, co-sponsored by the American Geophysical Union and the American Society of Limnology and Oceanography, had a session of invited and contributed papers on undergraduate and graduate education. An evening session dealt with "Alternative Careers." These followed by $10 \mathrm{mo}$ a Panel on Education in the Ocean Sciences: "Careers and Curricula" at The Oceanography Society's Fourth Scientific Meeting, April, 1995 (Sharp, 1995). Two common themes discussed during these meetings (and other gatherings), were 1) Is there an oversupply of $\mathrm{PhDs}$ in oceanography? and 2) how can we make more rapid, substantial progress in expanding the opportunities for underrepresented minorities in the ocean sciences?

We believe it is instructive to examine briefly how these topics were viewed within one sector of the ocean sciences community over a decade ago, and one response of that sector of the ocean sciences community. Some readers may discover a certain irony in what follows with respect to the present concerns of some of our colleagues and graduate students about having "too many" graduate students studying for the PhD in oceanography and ocean engineering.

At the suggestion of co-author Peirson and the leadership of C. D. Hollister and A. R. M. Nowell, the deans or department chairs of the Joint Oceanographic Institution (JOI) schools initiated in 1980 a series of biennial meetings to assess and discuss issues of mutual interest, e.g.. curricula, admissions procedures, supply of

John W. Farrington and A.L. Peirson, III, Woods Hole Oceanographic Institution, Woods Hole, MA 02543, USA. applicants, demands of the profession, quality of applicants and students, recruiting, minority, and gender-related issues. In 1988. Nowell and Hollister (1988) summarized the major findings of the "Dean's Retreats," and among their predictions they noted that national demographic patterns would result in difficulties in recruiting qualified students to certain subdisciplines of oceanography. Indeed, at the 1985 Dean's Retreat, the collective data from the JOI schools confirmed what several schools had suspected from their own experience in the prior 2-3 yr-a downward trend in numbers of applicants to the larger (JOI) oceanography graduate programs.

Although the major drop-off in applicant numbers had been in the biological areas, the trend was also evident in the physical sciences. The concern with biological oceanography was somewhat less bothersome because the ratio of applicants to admissions openings in biological oceanography still remained very high. The data from the JOI schools showed that the applicant pools applying to the JOI schools nationwide for physical oceanography and chemistry were dangerously small; $<70$ in chemistry: $<100$ in physical oceanography (from Nowell, unpublished).

These trends led to a search for strategies to attract greater numbers of qualified applicants from physical sciences and mathematics to graduate programs in oceanography. One proposed plan was to work more closely with the people who play a major role in undergraduate student career choices; the undergraduate faculty. To that end, a proposal was submitted to the Office of Naval Research, and funds were made available for $2 \mathrm{yr}$ to develop a network of knowledgeable undergraduate faculty advisors at colleges and universities to whom undergraduates could turn for guidance when expressing an interest indicating that the student might wish to explore a career in oceanography.

The strategy adopted to teach undergraduate college faculty about today's oceanography was to bring them to a workshop at an oceanographic institution, school, or department where they would be exposed to active oceanographers, to ongoing research, and to graduate students in the process of learning, doing this in a small enough group to encourage personal contacts and feedback. The Office of Naval Research funding was limited to undergraduate faculty in physics, mathematics, engineering, and to a lesser extent chemistry. Additional funds from the Pew Memorial Trust expanded the program to include the disciplines of biology and geology. The initial workshops in 1987 were held at the University of Washington and at Woods Hole Oceanographic Institution. In 1989, Scripps Institution of Oceanography was added. and three workshops were convened. In 1992, a workshop was held at Woods Hole Oceanographic Institution. A detailed account of these workshops is available from the authors, and we paraphrase below from sections of the report.

At the same time as the College Faculty Workshops for undergraduate faculty were being organized and convened, the situation they were designed to address was changing, although data demonstrating this had not been assembled and interpreted at the time of the first workshop. The downward trend in the number of applicants slowed and even reversed slightly in 1985 and 1986, and 1988 marked the start of a significant increase in the overall applicant pool (Nowell and Hollister, 1990). The most noticeable 
change occurred in Physical Oceanography, Biological Oceanography and to a lesser extent in Chemical Oceanography. In essence, the main motivation for the workshop experiment, as proposed in for certain the causative factors, although we suspect that the realization of the downward trend in applications by individual schools and departments, reinforced by the 1985 JOI "Deans Retreat" consensus, led to increased efforts at personal recruitment by the faculty and changes in advertising strategies. This may have intersected with an increased interest in environmental sciences nationwide.

What did not change, even with the increase in applications, was the need to address underrepresentation of minorities in ocean sciences and ocean engineering. As a result of the increased efforts to attract minorities to ocean sciences and ocean engineering by the JOI schools and by the Office of Naval Research, a specific effort was made for the 1989 workshops to increase the involvement of faculty from institutions where minorities enrollment has been traditionally a high percentage of the students. These efforts were increased again for the 1992 workshop as described below.

\section{Workshop Preparation and Execution}

\section{Recruiting and Advertising for the Workshops}

Initially the workshops focused on two specific groups of colleges and universities: those with strong physics, mathematics, and engineering programs, and the strong liberal arts colleges 1986, had diminished. We cannot state

identified in the Oberlin College study on "The Future of Science at Liberal Arts Colleges" known as the "Oberlin 50." Advertisements were placed in the Chronicle of Higher Education, Physics Today, The Physics Teacher, and Spectrum (IEEE Journal) and a special announcement was direct-mailed to the presidents and science department chairs at the Oberlin 50 colleges and to individual undergraduate faculty identified by colleagues in the graduate programs in ocean sciences.

In 1989, more attention was focused on attracting faculty from the historically black schools and minority institutions, while still trying to attract faculty from the two groups mentioned above. Advertisements were again placed in The Physics Teacher and Physics Today, and a special mailing list was prepared (350 names). which included all past participants, the "Oberlin 50" colleges" science department chairs, a selected list of department chairs at historically black or predominantly black minority institutions. and recommended individuals. The mailing included an announcement and a personal letter describing the intent of the workshop.

Advertising in 1992 was reduced to ads in the The Chronicle of Higher Education and The Scientist and mailings to all past participants and their schools. In addition. we expanded the list of minority institutions and undergraduate faculty mentoring minority students by seeking advice from individuals active in minority education in marine sciences and telephoning each of the schools and departments they suggested

Table 1

Gender and Minority Distribution of Workshop Applicants and Participants

\begin{tabular}{|c|c|c|c|c|c|c|c|c|}
\hline \multirow[b]{2}{*}{ Probe } & \multicolumn{2}{|c|}{ Total } & \multicolumn{2}{|c|}{ Male } & \multicolumn{2}{|c|}{ Female } & \multicolumn{2}{|c|}{ HPBCU* } \\
\hline & No. & Percent & No. & Percent & No. & Percent & No. & Percent \\
\hline \multicolumn{9}{|l|}{1987} \\
\hline Applicunts & 73 & $100 \%$ & 60) & $82 \%$ & 13 & $18 \%$ & 3 & $4 \%$ \\
\hline Participants & 37 & $100 \%$ & 31 & $84 \%$ & 6 & $16 \%$ & 1 & $3 \%$ \\
\hline \multicolumn{9}{|l|}{1989} \\
\hline Applicants & 67 & $100 \%$ & 57 & $85 \%$ & 10 & $15 \%$ & 9 & $13 \%$ \\
\hline Participants & 49 & $100 \%$ & 45 & $92 \%$ & 4 & $8 \%$ & 7 & $14 \%$ \\
\hline \multicolumn{9}{|l|}{1992} \\
\hline Applicants & 42 & $100 \%$ & 34 & $81 \%$ & 8 & $19 \%$ & 11 & $26 \%$ \\
\hline Participants & 20) & $100 \%$ & 16 & $80 \%$ & 4 & $20 \%$ & 6 & $30 \%$ \\
\hline \multicolumn{9}{|l|}{ Totals } \\
\hline Applicants & 182 & $100 \%$ & 151 & $83 \%$ & 31 & $17 \%$ & 23 & $13 \%$ \\
\hline Participants & 106 & $100 \%$ & 92 & $86 \%$ & 14 & $13 \%$ & 14 & $13 \%$ \\
\hline
\end{tabular}

* Historically and predominently black colleges/universities: values in this column do not contribute to the values in the Total column. to obtain the names of the appropriate college or university president. provost. dean, or department chair who should receive a personal letter about the workshops.

\section{Applicants}

Overall, the College Faculty Workshops in Oceanography and Ocean Engineering drew serious interest from $>200$ individuals. Final complete and eligible applicants totaled 182, (Table 1) with close to half coming from liberal arts college faculty, and the next largest group (32\%) from comprehensive universities. As intended, we succeeded in attracting a large group of physics/math professors $(28 \%)$ and as expected an equally large group of biology professors. Equal numbers of chemists and geologists applied $(17 \%)$ with engineering being the smallest group $(10 \%)$.

Applicants. 1987. In 1987 the advertising and direct mail announcement resulted in $>100$ serious inquiries and after eliminating those ineligible (17 applied from 2-year colleges) and the incomplete applications, there were 73 applicants, representing all categories of schools, and all major disciplines. Women faculty represented $18 \%$ of the pool, and three applicants $(4 \%)$ were from minority institutions. As intended. the majority (close to $65 \%$ ) of applicants were from liberal arts colleges, and the targeted discipline groups of physics/ math and engineering professors made up $43 \%$ of the total pool. The next largest group was represented by biologists $(29 \%)$, which is not at all surprising given the fact that many people understand "oceanography" to be primarily "marine biology" or "biological oceanography."

Applicants, 1989. The makeup of the applicant pool changed somewhat in 1989, as intended with our extra efforts at making the underrepresented minority colleges and universities aware of the program. A higher percentage of comprehensive universities were represented $(28 \%)$, and fewer liberal arts school faculty applied (only $44 \%$ ). Again, the major discipline group of the applicants was physics/math, with the geology group being the second largest component of the applicant pool. A disappointingly small number of women applied (10 or $15 \%)$, but the minority representation increased to $13 \%$ (9 individuals from 7 different universities). 
Applicants, 1992. The applicant pool for the 1992 workshop was much smaller than had been expected. Only a total of 44 people applied, 2 were ineligible, and 9 represented schools that had already had participants involved in previous workshops, leaving an effective pool of 33 people. We suspect that increased opportunities for undergraduate faculty summer research and increased interest in summer workshops for $\mathrm{K}-12$ science and math teachers taught by undergraduate faculty may have contributed to the low numbers of applicants. The exact reasons are unknown.

The planned workshops at the University of Washington and Scripps Institution of Oceanography were cancelled. and the 1992 summer effort was consolidated with all applicants at WHOI for ease of logistics. The largest number of applicants came from comprehensive universities $(48 \%)$, but the discipline distribution changed, with biologists making up the largest percentage $(40 \%)$ of the applicant pool and all other disciplines with about equal numbers of applicants (4-6). Almost 20\% of the pool were women, and minority institution representation was the highest of all years, with 11 individuals representing 10 different colleges/universities. In addition, one applicant from SUNY/Geneseo was Hispanic.

\section{Participants}

In selecting the participants, several factors were taken into consideration. but the one key factor was their contact with undergraduate students. Information was requested about their teaching loads, advising activities. and other academic responsibilities. and this information helps select appropriate participants. For the 1987 and 1989 workshops, care was taken to balance the groups at the different locations and take into account the participants' choice of location. A summary of the participant distribution according to gender and also those from Historically and Predominantly Black Colleges/Universities is present in Table 1 . The breakdown by disciplines, by workshop year, and by Carnegie Classification of Category of the college or university is set forth in Table 2. The colleges and universities represented at the workshops are listed in Table 3.

\section{Workshop Programs}

The original purpose behind these workshops was to find a way to increase the level of interest in oceanography as a career among science and engineering undergraduates. We recognized that a large part of the decrease in apparent interest was due to the general downward trend in science and engineering graduate enrollments. But we also believe that there was a growing lack of interest in oceanography. Much of the cause of the lack of interest can be traced to a lack of understanding of what modern oceanography and ocean engineering are, what type of background one needs to pursue graduate work in these

Table 2

Participant Distributıon by Carnegie Category of School and Applicant's Primary Discipline by Year

\begin{tabular}{|c|c|c|c|c|c|c|c|c|c|c|c|c|}
\hline \multirow[b]{2}{*}{ Carnegie Category } & \multicolumn{2}{|c|}{ Total } & \multicolumn{2}{|c|}{ Biology } & \multicolumn{2}{|c|}{ Chemistry } & \multicolumn{2}{|c|}{$\begin{array}{l}\text { Geology } \\
\text { Geophysics }\end{array}$} & \multicolumn{2}{|c|}{$\begin{array}{l}\text { Physics } \\
\text { Math }\end{array}$} & \multicolumn{2}{|c|}{ Enginecring } \\
\hline & No. & Percent & No. & Percent & No. & Percent & No. & Pcrcent & No. & Percent & No. & Percent \\
\hline \multicolumn{13}{|l|}{$\begin{array}{l}\text { I. Research Intensive } \\
\text { University }\end{array}$} \\
\hline 1987 & 2 & & 0 & & 0 & & 0 & & 0 & & 2 & \\
\hline 1989 & 5 & & 0 & & 0 & & 1 & & 4 & & 0 & \\
\hline 1992 & $\underline{2}$ & & $\underline{0}$ & & $\underline{0}$ & & $\underline{0}$ & & $\underline{0}$ & & $\underline{2}$ & \\
\hline & $\overline{9}$ & $8.5 \%$ & 0 & & 0 & & $\overline{1}$ & & $\overline{4}$ & & $\overline{4}$ & \\
\hline \multicolumn{13}{|c|}{$\begin{array}{l}\text { II. Other Doctorate Grantıng } \\
\text { Universities }\end{array}$} \\
\hline 1987 & 1 & & 0 & & 0 & & 0 & & 1 & & () & \\
\hline 1989 & 8 & & 2 & & 1 & & 0 & & 3 & & 2 & \\
\hline 1992 & $\underline{1}$ & & $\underline{0}$ & & () & & $\underline{0}$ & & $\underline{0}$ & & 1 & \\
\hline \multicolumn{13}{|c|}{ III. Comprehensive Universities } \\
\hline 1987 & 4 & & 1 & & 0 & & 0 & & 2 & & 1 & \\
\hline 1989 & 12 & & 2 & & 1 & & 3 & & 5 & & 1 & \\
\hline 1992 & $\underline{11}$ & & $\underline{6}$ & & 1 & & $\underline{2}$ & & $\underline{0}$ & & $\underline{\underline{2}}$ & \\
\hline & 27 & $25.5 \%$ & 9 & & 2 & & 5 & & 7 & & $\overline{4}$ & \\
\hline \multicolumn{13}{|l|}{ IV. Liberal Arts Colleges } \\
\hline 1987 & 28 & & 6 & & 8 & & 3 & & 11 & & 0 & \\
\hline 1989 & 24 & & 4 & & 5 & & 8 & & 7 & & 0 & \\
\hline 1992 & 5 & & 0 & & $\underline{2}$ & & 1 & & 1 & & $\underline{1}$ & \\
\hline & 57 & $53.8 \%$ & 10 & & 15 & & 12 & & 19 & & 1 & \\
\hline \multicolumn{13}{|l|}{ V. Specialized Institutions } \\
\hline 1987 & 2 & & 0 & & 0 & & 0 & & 1 & & 1 & \\
\hline 1989 & 0 & & 0 & & 0 & & 0 & & 0 & & 0 & \\
\hline 1992 & 1 & & $\underline{0}$ & & $\underline{0}$ & & 1 & & $\underline{0}$ & & () & \\
\hline & 3 & $2.8 \%$ & 0 & & 0 & & $\overline{1}$ & & $\overline{1}$ & & $\overrightarrow{1}$ & \\
\hline 1989 & 49 & & 8 & & 7 & & 12 & & 19 & & 3 & \\
\hline 1992 & 20 & & 6 & & 3 & & 4 & & 1 & & 6 & \\
\hline Grant Total & 106 & & 21 & & 18 & & 19 & & 35 & & 1.3 & \\
\hline Percent & & $100.0 \%$ & & $19.8 \%$ & & $17.0 \%$ & & $17.9 \%$ & & $33.0 \%$ & & $12.3 \%$ \\
\hline
\end{tabular}


Table 3

List of Participating Colleges and Universities by Carnegie Categories

1. Research Intensive Universities (8)

Columbia University; New York. New York

Georgia Institute of Technology; Atlanta, Georgia

Pennsylvania State University: University Park, Pennsylvania

University of Illinois; Urbana. Illinois

University of Kentucky; Lexington. Kentucky

University of Maryland: College Park. Maryland

University of Pennsylvania; Philadelphia, Pennsylvania

University of Pittsburgh; Pittsburgh. Pennsylvania

II. Other Doctoral-Graduating Universities (8)

*Atlanta University-Clark: Atlanta, Georgia

Baylor University: Waco. Texas

Hofstra University: Hempstead. New York

*Howard University; Washington, District of Columbia

Tufts University: Medford, Massachusetts

University of New Orleans; New Orleans, Louisiana

University of Vermont; Burlington, Vermont

West Virginia University; Morgantown. West Virginia

III. Comprehensive Universities (26)

Alfred University; Alfred, New York

Elon College; Elon College. North Carolina

*Florida A\&M University: Tallahassee, Florida

Gustavus Adolphus University: Saint Peter, Minnesota

*Jackson State University; Jackson. Mississippi

LaSalle University; Philadelphia, Pennsylvania

Loyola Marymount University; Los Angeles, California
Manhattan College; Riverdale, New York

Michigan Technological University: Houghton Michigan

Montana College of Minerals Science \& Technology: Butte. Montana

New Mexico Highlands University: Las Vegas, New Mexico

Northeastern State University; Tahlequah, Oklahoma

Mount Holyoke College; S. Hadley, Massachusetts

Muhlenberg College: Allentown, Pennsylvania

Oberlin College; Oberlin, Ohio

Ohio Wesleyan College; Delaware, Ohio

Pomona College; Claremont, California

St. Olaf College; Northfield, Minnesota

* Stillman College; Tuscaloosa, Alabama

Trinity College; Hartford, Connecticut

Union College; Schenectady, New York

University of Maryland-Eastern Shores; Princess Ann, Maryland

Vassar College; Poughkeepsie, New York

Wellesley College; Wellesley, Massachusetts

Wesleyan University; Middletown, Connecticut

Wheaton College; Wheaton. Illinois

Williams College; Williamstown, Massachusetts

V. Specialized Institutions (3)

Harvey Mudd College; Claremont. California

Milwaukee School of Engineering; Milwaukee, Wisconsin

South Dakota School of Mines; Rapid City, South Dakota

VI. Other

CICESE/OCEANOGRAPHY; Baja California, Mexico

\footnotetext{
* Historically and predominantly black colleges/universities
}

fields, and little understanding of the excitement of the current research. With this in mind, a program format was developed to provide an overview of the field, presented at a fairly basic level, and exposure to ongoing research through lectures, seminars, and visits to laboratories.

The format for each workshop was varied according to the opportunities available at each site, but the basic elements were the same. As an example, at WHOI, overview lectures on subdisciplines of oceanography and ocean engineering were presented the first day. The lectures were designed to help give the participants an appreciation for both the breadth of each subdiscipline, and more important, the interrelationships between subdisciplines. These were followed during the week by in-depth talks in each subdiscipline, visits to laboratories for demonstrations of ongoing research, visits with the graduate students, and attendance at the regular department seminars for reports on research in progress. Interspersed throughout the week were social occasions, primarily at mealtime, that provided excellent opportunities for discussion and feedback from the participants. Toward the end of the workshop we devoted some time to a wide-ranging open discussion on topics such as how the participants planned to act as "affiliate advisors" on their campuses and how we could improve future workshops. In the 1992 workshop we focused one discussion on the issue of "undergraduate education in oceanography."

The greatest value of the round-table discussion at WHOI was the interactions between workshop participants. It was an opportunity for many of them to compare programs and teaching styles and there was free exchange of ideas on methodologies for teaching. The discussion also allowed us to provide more information on background preparation for graduate school in oceanography.

General feedback on the format. scheduling, and amenities was very positive. We learned from the first year that more time with the graduate students was desirable and made that adjustment. We also learned to give the participants a little more free time so they had a chance to socialize with each other outside the confines of the structured workshop environment. From the perspective of the participants and ourselves, we believe the format and general schedule is a good one and that if future workshops are held for this purpose the same general pattern should be followed.

\section{Impact of the Workshops and Framework for Future Assessments}

It was recognized from the time that the workshops were first conceived that, in the short term, it would be highly unlikely that any accurate measure of direct impact of the workshops on graduate enrollment in oceanography would be attainable. The notion that we could clearly credit specific recruits to oceanography to the participants in the workshops across the entire spectrum of oceanography programs in the country is unrealistic. In fact, even trying to make that correlation for students who have entered the graduate programs at the University of Washington, Scripps Institution of Oceanography, and the Massachusetts Institute of Oceanography/ Woods Hole Oceanographic Institution Joint Program is fraught with difficulties and speculations. Although we know of a few isolated cases where our "affiliate advisors" have been instrumental in steering a student into applying, what we do not know, of course, is whether that student would have entered oceanography anyhow.

We believe that the workshops have been successful and that, although not measurable in an easily identifiable (to us) quantitative manner, they will in the long run have very positive benefits to the ocean sciences and ocean engineering communities. Some are listed below.

1. At the simplest level, oceanography and ocean engineering received national 
publicity within the professions of scientist. engineers, and educators, when an attractive advertisement was placed in national (and international in some cases) journals like Science, Spectrum, The Scientist, and the Chronicle of Higher Education.

2. We have established a much closer relationship with the 107 undergraduate faculty at the 86 colleges and universities who participated in the workshops. A special effort is being made to maintain that relationship by keeping these people on our mailing lists. This connection can only improve overall contacts with the undergraduate science and engineering communities, which is vitally important to successful recruitment of the best students.

3. The workshops provided a unique opportunity to impart a considerable amount of information on the field of oceanography to a diverse, geographically widely distributed group of interested faculty.

It was clear to us from some of the feedback we received that many of the participants learned a great deal about the field and went away with a much better understanding of what oceanographers and ocean engineers do, why they do it, and what it takes to be a graduate degree level oceanographer or ocean engineer. A comment made by one physics professor from Bryn Mawr seems to capture best the success of the workshops. He wrote: "The week was a very intensive educational experience. I found myself fascinated by the variety of the problems that you in the oceanographic community study, impressed by the quality and the diversity of the intellectual and technological arsenals that you bring to bear on them, dazzled by many of your results, and convinced of the seriousness of your manpower needs. Just as importantly perhaps, I also saw your excitement and the fun you all seem to have doing what you do."

Thinking about possibilities to assess the impact of the workshops on recruitment to graduate studies in oceanography led us to the realization that we know of no concerted national effort to collect information from incoming graduate students as to why they chose to enter graduate school in oceanography or ocean engineering and how they were first exposed to studies of the ocean. We believe that this is an important subject for discussion at future ocean science education meetings convened by any or all of several groups such as The Oceanography Society or the Consortium on Ocean Research and Education.

\section{Participant Feedback}

The feedback from the participants in the workshops was positive and constructive. The constructive suggestions can be conveniently grouped and paraphrased as follows:

1. Field component. A field component to the workshop; a short day trip in small groups on a coastal research vessel to demonstrate some of the field sampling techniques.

Our response: This could be arranged depending on the schedule of coastal vessels and if funding could be secured for the vessel operation. If we consider coastal vessels of the 10 to 20 meter range, and reasonable working and teaching space, at least two trips per workshop for a total of twenty undergraduate professors would be needed.

2. Hands-on laboratory projects. A short period of hands-on experience in the laboratory might be desirable, matching each workshop participant with an advisor.

Our response: Experience with, and feedback from, several visitors over the years suggest that it is difficult to convey the actual hands-on research experience in only a 1 - or 2-day laboratory stay. More demonstration type activities might be an acceptable response to this suggestion.

3. Joint research projects. Several workshop participants recommended that there be opportunities for them to have their own funded small-scale oceanography or ocean engineering-related research projects in their home institutions. The concept is to involve both undergraduate students and faculty in the research. The projects could be connected to larger projects or be part of projects ongoing at the graduate departments or schools at the larger institutions of oceanography. Aspects of this concept underpin one of the National Science Foundation Undergraduate Faculty Research Award categories for the sciences and engineering in general.

Our response: This type of activity should be encouraged and depends very much on faculty contact between institutions, colleges, and universities. We are aware of some examples of this type of activity. but it does not appear to be common practice. We expect that present funding constraints in ocean sciences and ocean engineering research would tend to mitigate against this type of activity. We seek reader feedback on this issue in particular.

\section{Concluding Comments}

We believe that the Undergraduate Faculty Workshops are a valuable means of educating those who educate and advise undergraduates about opportunities for graduate study and research in oceanography and ocean engineering, and subsequent career opportunities. In particular. we believe that continued involvement of undergraduate faculty from institutions with high enrollments of minorities in the types of workshops we have described will accelerate the increased representation of minority students in graduate studies in all aspects of oceanography and ocean engineering. Furthermore, the types of joint research efforts outlined in 3) (above) should be explored as soon as possible. This may prove to be a key mechanism in recruiting more minority undergraduate students to graduate studies in oceanography and ocean engineering.

\section{Acknowledgements}

We thank Charles D. Hollister and Arthur R.M. Nowell for their leadership in initiating the workshops and for being major contributors to the first two workshops. Numerous colleagues at the University of Washington. Scripps Institution of Oceanography, Woods Hole Oceanographic Institution, and Massachusetts Institute of Technology contributed to the success of the workshops. We thank the Office of Naval Research for financial support of the Undergraduate College Faculty Workshops, Contract NOOO14-K-87007 and Grant Number NOOO14-89-J1650. Contribution Number 9301 of the Woods Hole Oceanographic Institution.

\section{References}

Nowell, A.R.M. and C.D. Hollister, 1988: Graduate students in oceanography: recruitment, success, and career prospects. Eox. $69(36)$. $834-835 ; 840-843$.

Nowell, A.R.M. and C.D. Hollister, 1990: Undergraduate and graduate education in occanography. Oceanus, 33 (fall), 31-38.

Sharp. J.H.. 1995: Diverse career possibilities and a broad oceanography curriculum. Oceanogra$p h y, 8,106-107$. 